\title{
Role of vitamin D3 level and Apo-B/Apo-A1 ratio in patients with unstable angina in Kerbala province, Iraq
}

\author{
Fadhil Jawad Al-Tu'ma, ${ }^{a}$ Zahraa Mohsen Mohammed and Haidar Hussein Al-Sarraf ${ }^{b}$
}

aDepartment of Biochemistry, College of Medicine, University of Kerbala, Iraq.

bDepartment of Internal Medicine, Al-Hussein Teaching Hospital, Al-Hussein Medical City, Kerbala Health Directorate, Iraq.

Correspondence to Zahraa Mohsen Mohammed (email: zahraa.alhadi1988@gmail.com).

(Submitted: 05 January 2017 - Revised version received: 29 January 2017 - Accepted: 22 February 2017 - Published online: 26 June 2017)

\begin{abstract}
Objectives Vitamin D deficiency may be responsible for endothelial dysfunction which in turn affects the onset and progression of coronary artery disease and its risk factors. The Apo B/Apo Al ratio indicates the balance between atherogenic and anti atherogenic particles, the higher the value, the higher is the cardiovascular risk. The aim of study is to find a possible association between unstable angina and vitamin D3, Apo A1, Apo B, and Apo B/Apo A1 ratio and other risk factors (age, body mass index and smoking).

Methods This case-control study was conducted during the period from Nov. 2015 to Sep. 2016. A total of 40 patients of unstable angina presented with typical chest pain to the coronary care unit in Al-Hussein Teaching Hospital, Al-Hussein Medical City/ Kerbala. The diagnosis was based on the clinical history and electrocardiography. A total of 50 persons were matched in age, gender and BMI as a control group. The procedures were measured using Auto Immunoassay Analyzer.

Results Vitamin D3 deficiency ( $<30 \mathrm{ng} / \mathrm{mL}$ ) was prevalent in unstable angina (UA) compared with controls (vitamin D3 $\geq 30 \mathrm{ng} / \mathrm{mL}$ ) (odds ratio $[\mathrm{OR}], 21.93 ; 95 \%$, confidence interval [Cl], 5.91-81.31; $P<0.001)$. The results obtained that serum $25(\mathrm{OH}) \mathrm{D} 3$ was highly significant in smoker compared with non-smoker in both groups $(P<0.001, P<0.05$, respectively). The serum Apo B, Apo A1 and Apo B/Apo A1 ratio were highly significant between both groups $(P<0.01, P<0.001, P<0.001$, respectively). On the other hand, vitamin D3 recorded significant correlation with each of the age and BMI in control group (all $P<0.01$ ).

Conclusion The present study showed a highly significant association between vitamin D3, Apo B, Apo A1 levels, Apo B/Apo A1 ratio and unstable angina as compared with the control group, and significant correlation between vitamin D3 and age, BMl and smoking.

Keywords unstable angina, vitamin D3, ApoA1, Apo B, Apo B/Apo A1 ratio
\end{abstract}

\section{Introduction}

Unstable angina (UA) is a type of angina pectoris that is irregular. It is also classified as a type of acute coronary syndrome. The term UA has been conventionally applied to patients with myocardial ischaemia without myocardial necrosis. The UA is differentiated from stable angina in that the pain is often of more recent onset with increasing frequency and severity, and unlike stable angina is often not relieved by rest, and can occur at rest and on minimal exertion.

The UA is considered to be present in patients with ischaemic symptoms suggestive of an acute coronary syndrome and no elevation in troponin, with or without ECG changes indicative of ischaemia (ST segment depression or transient elevation or new T wave inversion). Since an elevation in troponin may not be detectable for up to 12 hours after presentation, UA and Non ST-segment elevation myocardial infraction are frequently indistinguishable at initial evaluation.

Unstable angina is caused by disruption of an atherosclerotic plaque with partial thrombosis and possibly embolization or vasospasm. ${ }^{3}$

The diagnosis of UA is characterized by at least one of the following:

1. Occurs at rest or minimal exertion and usually lasts more than 20 minutes (if nitroglycerin is not administered)

2. Being severe and of new onset (within 1 month)

3. Occurs with a crescendo pattern (brought on by less activity, more severe, more prolonged or increased frequency than previously).

Nitroglycerin can be used immediately to widen the coronary arteries and help increase blood flow to the heart.
In addition, nitroglycerin causes peripheral venous and artery dilation reducing cardiac preload and afterload. These reductions allow for decreased stress on the heart and therefore lower the oxygen demand of the heart's muscle cells. Antiplatelet drugs such as aspirin and clopidogrel can help to reduce the progression of atherosclerotic plaque formation, as well as combining these with an anticoagulant such as a low molecular weight heparin. ${ }^{2}$

Traditionally, vitamin D3 has been a well-known vital nutrient for calcium homeostasis and healthy bones. However, recent researches reveal that vitamin D3 is associated with numerous outcomes including not only rickets or osteomalacia but also as a potential influencing factor in the pathogenesis of several chronic non-skeletal diseases, such as cancer, immunity disorders, CVD and problems in pregnancy, because the discovery that the vitamin $\mathrm{D}$ receptor (VDR) is ubiquitously expressed in almost all body cells. ${ }^{5}$ Since then, several, but not all, observational studies that have been published indicated that low vitamin D3 levels are associated with higher incidence of cardiovascular events and mortality. ${ }^{6-9}$ There is strong observational epidemiologic evidence that suggests that low levels of serum 25(OH)D3 are a novel risk factor for all-cause mortality, cardiovascular mortality, CHD events, stroke, and heart failure. Suboptimal vitamin D3 is thought to influence CVD risk by acting on established risk factors such as hypertension, diabetes, and inflammation. ${ }^{10}$

The Apo B and Apo AI are the two major apolipoproteins involved in lipid transport and independent predictors of $\mathrm{CVD}$ in the general population. The Apo B/Apo AI ratio 
indicates the balance between atherogenic and anti atherogenic particles, the higher the value, the higher is the cardiovascular risk. It may be a better marker of the CVD risk than conventional lipid measurements. ${ }^{11-13}$

Previous reports have shown that Apo B/Apo AI ratio for men and women, respectively, $<0,7$ and $<0,6$ is associated with low risk for CVD. The advantage of calculating this index is that the concentration of apolipoproteins does not change after the meal and do not change in different times of day. In addition, with regards to the tests performed after AMI have occurred there is no matter how much time has elapsed since the in the blood collection. ${ }^{14}$

The aim of the study is to find a possible association between unstable angina and vitamin D3, Apo A1, Apo B, and Apo B/Apo A1 ratio and other risk factors (age, body mass index (BMI) and smoking) in Kerbala province.

\section{Materials and Methods}

This case-control study was conducted during the period from Nov. 2015 to Sep. 2016. A total of 40 male patients of unstable angina had been selected from coronary care unit (CCU) in AL-Hussein Teaching Hospital/AL-Hussein Medical CityKerbala Health Directorate/Holy Kerbala - Iraq. The (mean \pm SD) of age is $(52.85 \pm 11.38)$ ranged between 28 and 72 years old. A total of 50 male individuals as control were matched with patients group in their age and body mass index, and the mean \pm SD of age is $52.72 \pm 8.74$ and ranged between 40 and 72 years old. Approvals of the study program were taken from the administration of Al-Hussein General Hospital, and from the patients and the controls groups.

Serum 25(OH)D3, Apo A1, Apo B, troponin I, random blood sugar (RBS), urea and creatinine. Serum 25(OH)D3 and troponin I levels were measured using Auto Immunoassay Analyzer [MAGLUMI CLIA (chemiluminescence immunoassay)] Serum Apo A1, Apo B, urea, creatinine and random blood sugar were measured using Auto Analyzer Biochemistry (Cormay).

\section{Statistical Analysis}

Statistical analysis was done by Statistical Package for the Social Sciences (SPSS 21). Descriptive statistics were presented as mean \pm standard deviation (SD) for continuous variables (Age, BMI, glucose, Apo A1, Apo B, Apo B/A1 ratio, urea, creatinine, troponin I and $25(\mathrm{OH}) \mathrm{D} 3)$. Independent samples student's $t$-test, Chi square, Fisher's exact test, correlation coefficient $(r)$ test were used to compare, assess and describe the association between the different studied variables; $P$ values $<0.05$ were considered to indicate statistical significance and highly significant if it is $<0.01$.

\section{Results}

The characteristics of population of this study are presented in Table 1. The results show the evaluation of vitamin D3, Apo B, Apo A1, Apo B/Apo A1 ratio, troponin I and urea. It has significant association between patient and control group. And no significant association in Creatinine and sugar between patients and control groups.

There was highly significant association between patient and control groups when classified vitamin D3 levels to sufficiency $(\geq 30)$ and deficiency $(<30)$, and the results are shown in Table 2 .
The odds ratio of this study of unstable angina was 21.93 (95\% confidence interval 5.91-81.31; $P<0.001$ ).

Table 3 presents the correlation between vitamin D3 and the age in two groups, and there was a significant correlation in patient group as shown in Fig. 1 and control group as shown in Fig. 2, and significant correlation between vitamin D3 and BMI in the control group as shown in Fig. 3.

A significant association was shown between smokers and non-smokers in patient group $(P<0.01)$. Additionally, it showed significant association between smokers and nonsmokers in control group $(P<0.05)$, as shown in Table 4 .

\section{Discussion}

\begin{tabular}{|c|c|c|c|}
\hline \multirow[b]{2}{*}{ Parameters } & \multicolumn{2}{|c|}{ Mean \pm SD } & \multirow[b]{2}{*}{$P$ value } \\
\hline & $\begin{array}{l}\text { Control } \\
(N=50)\end{array}$ & $\begin{array}{l}\text { Patient } \\
(N=40)\end{array}$ & \\
\hline 25(OH)D3 (ng/ml) & $35.15 \pm 11.79$ & $16.93 \pm 4.85$ & $<0.001^{* *}$ \\
\hline Apo B (mg/dl) & $98.05 \pm 37.73$ & $115.75 \pm 43.16$ & $0.041^{*}$ \\
\hline Apo A1 (mg/dl) & $144.49 \pm 28.16$ & $117.74 \pm 25.48$ & $<0.001^{* *}$ \\
\hline Apo B/A1 & $0.68 \pm 0.21$ & $1.01 \pm 0.39$ & $<0.001^{* *}$ \\
\hline Troponin I (pg/ml) & $6.37 \pm 1.78$ & $25.62 \pm 40.16$ & $0.001^{* *}$ \\
\hline Urea (mg/dl) & $30.34 \pm 5.86$ & $33.90 \pm 5.08$ & $0.003^{* *}$ \\
\hline Creatinine (mg/dl) & $0.91 \pm 0.17$ & $1.01 \pm 0.16$ & 0.39 \\
\hline Sugar (mg/dl) & $108.40 \pm 13.15$ & $109.60 \pm 14.19$ & 0.68 \\
\hline
\end{tabular}

*Significant association $P<0.05$; **High Significant association $P<0.01$

\begin{tabular}{|c|c|c|c|}
\hline & & & \\
\hline & & Patient & Control \\
\hline \multirow{4}{*}{ 25(OH)D3 Category } & \multirow{2}{*}{$<30$} & 37 & 18 \\
\hline & & $92.5 \%$ & $36.0 \%$ \\
\hline & \multirow{2}{*}{$\geq 30$} & 3 & 32 \\
\hline & & $7.5 \%$ & $64.0 \%$ \\
\hline$P$ value & & $<0.001^{* *}$ & \\
\hline \multirow{2}{*}{ Total } & & 40 & 50 \\
\hline & & $100 \%$ & $100 \%$ \\
\hline
\end{tabular}

**Highly significant association $P<0.01$.

Table 3. Correlation between vitamin D3 and the age, BMI in patient and control groups

\begin{tabular}{|c|c|c|c|c|c|c|}
\hline \multirow{2}{*}{\multicolumn{2}{|c|}{ Case type }} & \multirow{2}{*}{$N$} & \multicolumn{2}{|c|}{ Mean \pm SD } & \multirow{2}{*}{$r$} & \multirow{2}{*}{ Pvalue } \\
\hline & & & 25(OH)D3 (ng/ml) & Age (year) & & \\
\hline \multirow{3}{*}{ Age } & Patient & 40 & $16.93 \pm 4.85$ & $52.85 \pm 11.38$ & -0.53 & $0.001^{* *}$ \\
\hline & Control & 50 & $35.15 \pm 11.79$ & $52.72 \pm 8.74$ & -0.47 & $0.001^{* *}$ \\
\hline & & & 25(OH)D3 (ng/ml) & BMI $\left(\mathrm{kg} / \mathrm{m}^{2}\right)$ & & \\
\hline \multirow{2}{*}{ BMI } & Patient & 40 & $16.93 \pm 4.85$ & $28.36 \pm 1.89$ & -0.1 & 0.52 \\
\hline & Control & 50 & $35.15 \pm 11.79$ & $29.55 \pm 2.01$ & -0.42 & $0.002^{* *}$ \\
\hline
\end{tabular}

**Highly significant correlation $P<0.01$ 


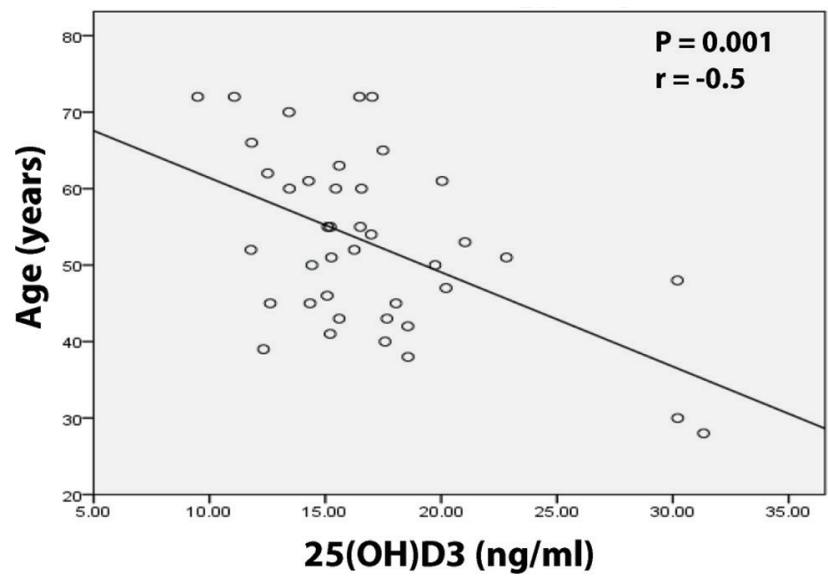

Fig. 1 Correlation between vitamin D3 and the age in unstable angina group.

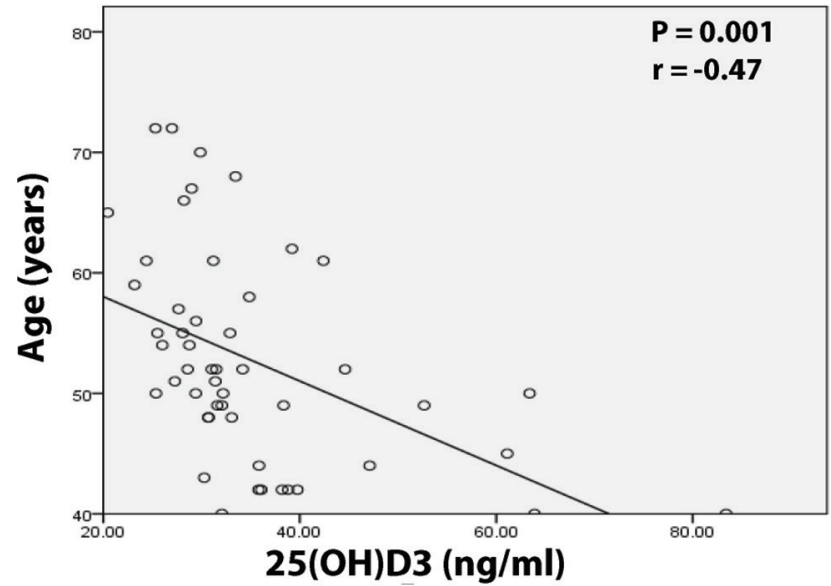

Fig. 2 Correlation between vitamin D3 and the age in control group.

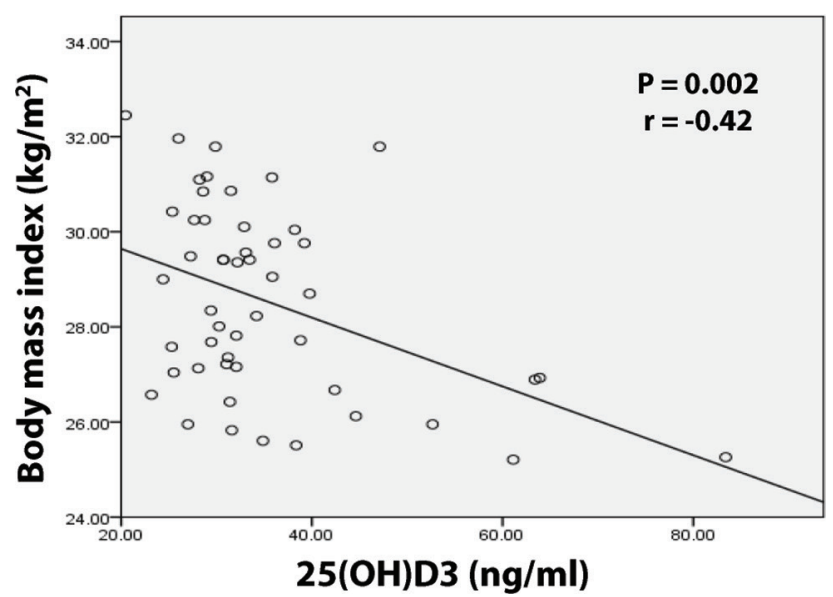

Fig. 3 Correlation between vitamin D3 and body mass index in control group.

In recent years, the researchers focused on vitamin D3 due to its effects on several organs such as cardiovascular system, in addition to its important role in the mineralization of bone. Most studies observed that low vitamin D3 levels were associated with a high risk of cardiovascular disease. ${ }^{15}$

The results of this study showed that the concentration of vitamin D3 was highly significant in the patient group as compared with the normal control group. This results were

Table 4. Comparison between vitamin D3 and smoking in
patients and control groups
\begin{tabular}{llllll} 
Parameter & Case type & Smokers & $\boldsymbol{N}$ & Mean \pm SD & P value \\
\hline $\begin{array}{l}\text { 25(OH)D3 } \\
(\mathrm{ng} / \mathrm{ml})\end{array}$ & Patient & Positive & 22 & $14.68 \pm 2.50$ & $0.001^{*}$ \\
& & Negative & 18 & $19.68 \pm 5.62$ & \\
& Control & Positive & 16 & $29.88 \pm 4.76$ & 0.029 \\
& & Negative & 34 & $37.63 \pm 13.28$ & \\
\hline
\end{tabular}

*Significant association $P<0.05$; **Highly Significant association $P<0.01$

in agreement with other case-control study in India. The database contained 100 patients (chronic stable angina) and 100 controls showed the same results, which reported that $75 \%$ of the IHD cases were vitamin D3 deficient $(<20 \mathrm{ng} / \mathrm{mL})$; while among the controls, $10 \%$ were vitamin D3 deficient. The deficiency vitamin D3 levels were highly significant with coronary artery disease, chronic stable angina $(P \leq 0.0001)^{16}$. The presented data were also in agreement with previous study in an Eastern European country observed an association between low serum concentration of vitamin D3 and ACS. The study included 60 ACS patients and 60 matched controls without ACS during a three-year follow up period. Vitamin D determination was performed in all study patients. The results of patients with ACS had a statistically significant mean vitamin D3 (low level of vitamin D3) as compared with control group (14.08 ng/ml vs. $23.23 \mathrm{ng} / \mathrm{ml}, P=0.001) .{ }^{17}$ Brøndum-Jacobsen et al. and $\mathrm{Ng}$ et al. observed the relationship between vitamin D3 and ischaemic heart disease, myocardial infraction and early death. ${ }^{18,19}$

The odds ratio of this study of risk unstable angina events was about 22 times higher in men with vitamin D3 levels $<30 \mathrm{ng} / \mathrm{ml}$ compared with those with levels $\geq 30 \mathrm{ng} / \mathrm{ml}$ (95\% confidence interval 5.91-81.31; $P<0.001$ ). This result agrees with Wang et al., which concluded that vitamin $\mathrm{D}$ deficiency is associated with incident CVD. The study contains 1739 participants without prior CVD. Vitamin D status was assessed by measuring vitamin D3 levels. Prespecified thresholds were used to characterize varying degrees of vitamin D3 deficiency $(<15 \mathrm{ng} / \mathrm{mL},<10 \mathrm{ng} / \mathrm{mL})$. During a mean follow-up of 5.4 years, 120 personal developed a first cardiovascular event. The risk of cardiovascular events was 1.62 times higher in those with vitamin D3 levels $<15 \mathrm{ng} / \mathrm{ml}$ versus the individuals with vitamin D3 $\geq 15 \mathrm{ng} / \mathrm{mL}$ (95\% confidence interval 1.11 to $2.36, P=0.01)$ and 1.80 (95\% confidence interval 1.05 to $3.08, P=0.01$ ) for levels $<10 \mathrm{ng} / \mathrm{ml}^{20}$

Several mechanisms proposed to explain the relation between vitamin D3 deficiency and CVD is that chronic vitamin D3 deficiency causes secondary hyperparathyroidism, acting through pathogenic pathways associated with PTH excess: increased pancreatic cell dysfunction and insulin resistance, predisposing to the metabolic syndrome and diabetes; increasing blood pressure (by activation of the renin angiotensin system), and leading to left ventricular hypertrophy (with subsequent apoptosis and fibrosis); and stimulation of systemic and vascular inflammation, augmenting atherogenesis. $^{20,21}$ Other studies suggest that parathyroid hormone has a proinflammatory effect, stimulating vascular smooth muscle cells to release cytokines. ${ }^{22}$ Known risk factors for CVD, including smoking, obesity, advanced age and inactivity (reduced sun exposure), are associated with lower vitamin D3, which make the dissection of the causal role of 
low vitamin D3 status in CVD difficult. Finally, recent evidence has suggested that vitamin D3 may be a negative acute phase reactant; so, chronic disease may lead to low vitamin D3 even in the presymptomatic phases of CVD..$^{23}$

The results of this study showed that vitamin D3 deficiency was highly significant with age in the control group, and in agreement with a previous study, which indicates that the odds for vitamin D3 deficiency increased with age, vitamin D3 level wall be less. They noticed that aging decreases the capacity of the human skin to produce vitamin D. They found that a 70-year old individual makes four times less vitamin D3 from the sun than a 20 year old personal. ${ }^{16}$

In this study, it was noticed that there a significant inverse association between vitamin D3 and BMI in the control group, increase of BMI leading to decrease vitamin D3, it's in line with other research. ${ }^{24}$ People who are obese, a (BMI $\geq 30$ ), are associated with lower serum vitamin D3 levels compared with non-obese individuals; people who are obese may need larger than usual intakes of vitamin D3 to achieve vitamin D3 levels comparable to those of normal weight. Obesity does not affect skin's capacity to synthesize vitamin D3, but greater amounts of subcutaneous fat sequester more of the vitamin and alter its release into the circulation. ${ }^{25}$

Some other studies indicate significant association between vitamin D3 and smokers, where the smoking associated with decrease vitamin D3, as shown in this study. In this study among adults, it was observed that lower vitamin D3 levels and higher prevalence of vitamin D3 insufficiency and deficiency in the adult male subjects with unstable angina in smokers rather than nonsmoker. Similar results have been seen in many other studies. ${ }^{26,27}$

Studies revealed the relationship between apolipoprotein (B and A1) and coronary artery disease, which is considered a strong indicator to detect the risk of coronary artery disease. ${ }^{28}$ In this study, it was observed a highly significant association between unstable angina and Apo B, Apo A1 and Apo B/Apo A1 ratio. It was found the significant association between $A p o B$ and unstable angina when compared with the control group, the greater Apo B the likelihood of increased risk of cardiovascular disease. This is in line with other study, ${ }^{29}$ and it was inversely associated significantly between Apo A1 and unstable angina when compared with control group, decrease Apo A1 leading to increase the risk of ischaemic heart disease. This agrees with another study. ${ }^{30}$ In addition to increase of the Apo B/Apo A1 ratio leading to high risk of unstable angina, these data were in agreement with other study. Database contains 45 participants with CVD and 44 healthy participants. There were significant differences in Apo B/Apo AI ratio $(P<0.05) .^{31}$

In this study, the results were not significantly associated between vitamin D3 and Apo B, Apo A1, Apo B/Apo A1 ratio. This result was in agreement with other study. It was observed that no significant association between vitamin D3 and (Apo B, Apo A1). ${ }^{32}$ vitamin D3 has been proposed to modulate the transcription activity of a group of genes known to be involved in lipid metabolism. In addition, it was suggested that vitamin D3 may upregulate lipoprotein lipase activity in adipocytes, and this will decrease circulating triglyceride levels. $^{32}$

\section{Conclusions}

According to the results of the study, it can be concluded that there was a highly significant association for level of vitamin D3 between patient and control groups. There was prevalent level of low vitamin D3 among patients. There was a significant inverse correlation between vitamin D3 level and the ages, BMI in the control group. There was a significant association between vitamin D3 level and the smoking. There was a significant correlation between Apo B, Apo A1 levels and Apo B/Apo A1 ratio with each of unstable angina and control groups. There was no significant effect of vitamin D3 on Apo B, Apo A1 levels and Apo B/Apo A1 ratio.

\section{Recommendation}

1. A screening program for vitamin D3 might be adopted to help in the prevention and control of Ischaemic heart disease.

2. Further studies with larger sample size, study the effect correction of vitamin D3 deficiency on secondary prevention of Ischaemic heart disease.

3. Study the correlation between vitamin D3 level and atrial natriuretic peptide (ANP) in Ischaemic heart disease and control groups.

\section{Conflict of Interest}

None.

\section{References}

1. Sandoval Y, Apple FS, Smith SW. High-sensitivity cardiac troponin assays and unstable angina. Eur Heart J Acute Cardiovasc Care. 2016 Jul 7:2048872616658591

2. Yeghiazarians Y, Braunstein JB, Askari A, Stone PH. Unstable angina pectoris New England Journal of Medicine. 2000;342:101-14

3. Maitra A, Abbas AK. The Endocrine System in Robbins and Cotran Pathologic Basis of Disease 7th edition. 2005 Chapter 24 pp.1218-1221. Edited by Kumar V. Abbas AK, Fausto N.

4. Braunwald E, Antman EM, Beasley JW, Califf RM, Cheitlin MD, Hochman $J S$, et al. ACC/AHA guideline update for the management of patients with unstable angina and non-ST-segment elevation myocardial infarction-2002: summary article. Circulation. 2002;106:1893-900.

5. Kwon HJ. Vitamin D receptor signaling is required for heart development in zebrafish embryo. Biochemical and biophysical research communications. 2016;470:575-8

6. Duranton F, Rodriguez-Ortiz ME, Duny Y, Rodriguez M, Daurès JP, Argilés A Vitamin D treatment and mortality in chronic kidney disease: a systematic review and meta-analysis. Am J Nephrol. 2013;37:239-48.

7. Zittermann A, lodice S, Pilz S, Grant WB, Bagnardi V, Gandini S. Vitamin D deficiency and mortality risk in the general population: a meta-analysis of prospective cohort studies. Am J Clin Nutr. 2012;95:91-100.

8. Bittner V, Wenger NK, Waters DD, DeMicco DA, Messig M, LaRosa JC. RETRACTED: Vitamin D levels do not predict cardiovascular events in statintreated patients with stable coronary disease. Am Heart J. 2012;164:387-393.

9. Pilz S, Kienreich K, Tomaschitz A, Lerchbaum E, Meinitzer A, März W, et al. Vitamin D and cardiovascular disease: update and outlook. Scand J Clin Lab Invest. 2012;72:83-91.

10. Michos ED, Lutsey PL. 25-hydroxyvitamin D levels and coronary heart disease risk reclassification in hypertension - is it worth the "hype"? Atherosclerosis. 2016;245:237-9.

11. Lamprea-Montealegre JA, Sharrett AR, Matsushita K, Selvin E, Szklo M, Astor BC. Chronic kidney disease, lipids and apolipoproteins, and coronary heart disease: The ARIC study. Atherosclerosis. 2014;234:42-6.

12. Jing F, Mao Y, Guo J, Zhang Z, Li Y, Ye Z, et al. The value of Apolipoprotein B/Apolipoprotein A1 ratio for metabolic syndrome diagnosis in a Chinese population: a cross-sectional study. Lipids Health Dis. 2014;13:81. 
13. Walldius $\mathrm{G}$. The apoB/apoA-I ratio is a strong predictor of cardiovascular risk. lipoproteins in health and diseases. 2012;95-148.

14. Walldius $G$, Jungner I. The apoB/apoA-I ratio: a strong, new risk factor for cardiovascular disease and a target for lipid-lowering therapy-a review of the evidence. J Intern Med. 2006;259:493-519.

15. Christakos S, Dhawan P, Verstuyf A, Verlinden L, Carmeliet G. Vitamin D: metabolism, molecular mechanism of action, and pleiotropic effects. Physiol Rev. 2016;96:365-408.

16. Ab Hameed Raina MS, Shah ZA, Changal KH, Raina MA, Bhat FA. Association of low levels of vitamin D with chronic stable angina: A prospective casecontrol study. North American J Med Sci. 2016:8:143.

17. Knežević Praveček M, Hadžibegović I, Cvitkušić Lukenda K, Raguž A, Dunđer I, Gabaldo K, et al. Vitamin D deficiency in patients with acute coronary syndrome: clinically relevant or just a bystander?. Cardiologia Croatica. 2015;10

18. Ng LL, Sandhu JK, Squire IB, Davies JE, Jones DJ. Vitamin D and prognosis in acute myocardial infarction. Int J Cardiol. 2013;168:2341-2346.

19. Brøndum-Jacobsen $P$, Benn M, Jensen GB, Nordestgaard BG. 25-Hydroxyvitamin $D$ levels and risk of ischemic heart disease, myocardial infarction, and early death. Arterioscler Thromb Vasc Biol. 2012;32:2794-802.

20. Wang TJ, Pencina MJ, Booth SL, Jacques PF, Ingelsson E, Lanier K, et al. Vitamin D deficiency and risk of cardiovascular disease. Circulation. 2008;117:503-11.

21. Anderson JL, May HT, Horne BD, Bair TL, Hall NL, Carlquist JF, et al. Relation of vitamin $\mathrm{D}$ deficiency to cardiovascular risk factors, disease status, and incident events in a general healthcare population. Am J Cardiol. 2010;106:963-8.

22. Martín-Ventura JL, Ortego M, Esbrit P, Hernández-Presa MA, Ortega L, Egido J. Possible role of parathyroid hormone-related protein as a proinflammatory cytokine in atherosclerosis. Stroke. 2003;34:1783-9.
23. Ford JA, MacLennan GS, Avenell A, Bolland M, Grey A, Witham M, RECORD Trial Group. Cardiovascular disease and vitamin D supplementation: trial analysis, systematic review, and meta-analysis. Am J Clin Nutr. 2014;100:746-55.

24. Vimaleswaran KS, Berry DJ, Lu C, Tikkanen E, Pilz S, Hiraki LT, et al. Causal relationship between obesity and vitamin D status: bi-directional Mendelian randomization analysis of multiple cohorts. PLoS Med. 2013;10:e1001383.

25. Malone M. Recommended nutritional supplements for bariatric surgery patients. Ann Pharmacother. 2008:42:1851-8

26. Jiang CQ, Chan YH, Xu L, Jin YL, Zhu T, Zhang WS, et al. Smoking and serum vitamin D in older Chinese people: cross-sectional analysis based on the Guangzhou Biobank Cohort Study. BMJ Open. 2016;6:e010946.

27. Shinkov A, Borissova AM, Dakovska L, Vlahov J, Kassabova L, Svinarov D. Winter 25-hydroxyvitamin D levels in young urban adults are affected by smoking, body mass index and educational level. Eur J Clin Nutr. 2015;69:355-60.

28. Khadem-Ansari MH, Rasmi Y, Rahimi-Pour A, Jafarzadeh M. The association between serum apolipoprotein $\mathrm{Al}$ and apolipoprotein $\mathrm{B}$ and the severity of angiographical coronary artery disease. Singapore Med J. 2009;50:610.

29. Mashayekhi NR, Sadrnia S, Chehrei A, Javaheri J. The correlation between serum apoA1 and B and coronary artery disease as well as its severity. Int Cardiovasc Res J. 2014:8:1.

30. Manson JE, Bassuk SS. Biomarkers of cardiovascular disease risk in women. Metabolism. 2015:64:S33-9.

31. Tamang HK, Timilsina U, Singh KP, Shrestha S, Raman RK, Panta P, et al. Apo $\mathrm{B} / \mathrm{Apo}$ Al ratio is statistically a better predictor of cardiovascular disease (CVD) than conventional lipid profile: a study from Kathmandu Valley, Nepal. J Clin Diagn Res. 2014;8:34-6.

32. García-Bailo B. Plasma vitamin D and biomarkers of cardiometabolic disease risk in adult Canadians, 2007-2009. Prevent Chronic Dis. 2013;10.

This work is licensed under a Creative Commons Attribution-NonCommercial 3.0 Unported License which allows users to read, copy, distribute and make derivative works for non-commercial purposes from the material, as long as the author of the original work is cited properly. 